\title{
FHL1 protein isoforms in Emery-Dreifuss muscular dystrophy
}

\author{
Esma Ziat ${ }^{*}$, Anne T Bertrand \\ From 1st French-Italian meeting on laminopathies and other nuclear envelope-related diseases \\ Marseille, France. 15-16 January 2015
}

Emery-Dreifuss muscular dystrophy (EDMD) is a hereditary muscular disorder characterized by early joint contractures, progressive muscular wasting and weakness of scapuloperoneal distribution, and at adult age, patients develop cardiac abnormalities with a high risk of sudden death [1]. EDMD encompasses both X-linked and autosomal inheritance due to mutations in the genes encoding the nuclear envelope proteins emerin, lamin A/C [2-4]. First mutations in the Four-and-a-half LIM domain 1 gene (FHL1) being responsible for $\mathrm{X}$-linked EDMD were described by Gueneau et al. [5]. The human FHL1 gene encodes three alternatively spliced isoforms, named FHL1A, FHL1B and FHL1C, with FHL1A being the most abundantly expressed protein isoform in striated muscle. There is still little known about the precise localization and functions of the three different FHL1 isoforms in human skeletal muscle. Here, we describe for the first time the subcellular localization of FHL1A, FHL1B, and FHL1C in vitro in differentiating human primary myoblasts.

Localization of FHL1 protein isoforms was studied at the myoblast and myotube stages by confocal microscope analysis. Endogenous FHL1B protein localization was detected by an anti-FHL1B specific antibody, while for FHL1A and FHL1C, as no efficient isoform-specific antibodies were available, an anti-Flag antibody was used to follow Flag-tagged FHL1A and Flag-tagged FHL1C protein expression, after lentiviral transduction of human primary myoblasts. Successful transduction was confirmed by western blotting of whole extracts from myoblasts and myotubes using an anti-Flag antibody. In human myoblasts, Flag-FHL1A and Flag-FHL1C showed both a cytoplasmic and a nuclear distribution, while the nuclear staining was more pronounced in Flag-FHL1C transduced myoblasts. Endogenous FHL1B protein gave a moderate cytoplasmic and a strong nuclear staining. During 6- and 12-days of human myoblast differentiation, localization of all three FHL1 protein isoforms shifted from the nucleus to the cytoplasm. In addition, all FHL1 protein isoforms were observed to co-localize with phalloidin-stained actin fibers. Collectively, these results indicate differentiation-related changes in expression and subcellular localization of the human FHL1 protein isoforms.

Published: 11 November 2015

\section{References}

1. Emery AE: Emery-Dreifuss muscular dystrophy - a 40 year retrospective. Neuromuscular disorders: NMD 2000, 10(4-5):228-32.

2. Bione S, Maestrini E, Rivella S, Mancini M, Regis S, Romeo G, et al: Identification of a novel $\mathrm{X}$-linked gene responsible for Emery-Dreifuss muscular dystrophy. Nature genetics 1994, 8(4):323-7.

3. Bonne G, Di Barletta MR, Varnous S, Becane HM, Hammouda EH, Merlini L, et al: Mutations in the gene encoding lamin A/C cause autosomal dominant Emery-Dreifuss muscular dystrophy. Nature genetics 1999, 21(3):285-8.

4. Di Barletta Raffaele M, Ricci E, Galluzzi G, Tonali P, Mora M, Morandi L, et al: Different mutations in the LMNA gene cause autosomal dominant and autosomal recessive Emery-Dreifuss muscular dystrophy. American journal of human genetics 2000, 66(4):1407-12.

5. Gueneau L, Bertrand AT, Jais JP, Salih MA, Stojkovic T, Wehnert M, et al: Mutations of the FHL1 gene cause Emery-Dreifuss muscular dystrophy. American journal of human genetics 2009, 85(3):338-53.

doi:10.1186/1750-1172-10-S2-O18

Cite this article as: Ziat and Bertrand: FHL1 protein isoforms in EmeryDreifuss muscular dystrophy. Orphanet Journal of Rare Diseases 2015 10(Suppl 2):018. 